\title{
Obtenção de mutantes de Aspergillus carbonarius via transformação genética mediada por Agrobacterium tumefaciens
}

\author{
Generation of Aspergillus carbonarius mutants by \\ Agrobacterium tumefaciens-mediated transformation method
}

\author{
Lígia Uno Lunardi' Carla Beatriz Fier $^{1}$; Fernando Yuldi Ashikaga²; \\ Luiz Rodrigo Morioka ${ }^{3}$, Maria Helena Pelegrinelli Fungaro ${ }^{4}$
}

\section{Resumo}

\begin{abstract}
Aspergillus carbonarius é um potente produtor de ocratoxina A, uma toxina que apresenta efeitos nefrotóxico e carcinogênico. O conhecimento de genes envolvidos em sua biossíntese pode contribuir para o desenvolvimento de medidas de controle. O método de transformação genética mediado por Agrobacterium tumefaciens tem sido demonstrado como uma importante ferramenta para a obtenção de mutantes insercionais visando à caracterização de novos genes. O objetivo deste trabalho foi adequar o método de transformação genética via A. tumefaciens para a linhagem ITAL187 de A. carbonarius e obter mutantes alterados para a produção de ocratoxina A. Conídios foram transformados para resistência a higromicina B usando a linhagem AGL-1 de A. tumefaciens. A freqüência média de transformação foi de 20,04 transformantes por $10^{5}$ conídios-alvo. A prova física da transformação foi obtida pela detecção do gene $h p h$ por PCR e Southern Blot. Esta última demonstrou que a integração do DNA exógeno ocorreu de forma aleatória no genoma fúngico. Dentre 238 transformantes, 12 (5,042\%) mostraram variações morfológicas. Três mutantes (T44, T47 e T188) com significativa redução e dois mutantes (T238 e T162) com aumento da capacidade de produção de ocratoxina A foram obtidos. A identificação dos genes nocauteados contribuirá para a compreensão da biossíntese desta toxina.
\end{abstract}

Palavras-chave: Aspergillus carbonarius. Ocratoxina A. Agrobacterium tumefaciens. Transformação genética. Mutantes insercionais.

\begin{abstract}
Aspergillus carbonarius is a potent ochratoxin A producer, a mycotoxin that has nephrotoxic and carcinogenic effects. The knowledge of genes involved in biosynthesis of this toxin may be useful for the development of detection and control methods. The Agrobacterium tumefaciens-mediated transformation method has been demonstrated as a powerful tool to obtain insertional mutants for the characterization of new genes. The aim of this work was to adapt the A. tumefaciens-mediated transformation method for ITAL187 strain of A. carbonarius and to obtain transformants with alteration in ochratoxin A production. Conidia were transformed to hygromicin B resistance using AGL-1 strain of A. tumefaciens. The transformation frequency was 20,04 transformants per $10^{5}$ target conidia. The transformation evidence was obtained by PCR and Southern Blot analysis. The last one showed us that
\end{abstract}

Bolsista PIBIC/CNPq/UEL - UEL

2 Aluno de mestrado do Programa de Genética e Biologia Molecular-UEL.

3 Aluno de doutorado do Programa de Tecnologia de Alimentos-UEL.

4 Docente do Depto. de Biologia Geral (CCB) da UEL. E-mail: fungaro@uel.br. 
the $h p h$ gene integration was randomly in the genome fungi. Among 238 transformants, a total of 12 $(5,042 \%)$ showed morphological variations. Three transformants (T44, T47 and T188) with consistently reduced and two transformants (T238 and T162) with increased ochratoxin A production were obtained. The identification of nocauted genes will contribute to ochratoxin A biosynthesis clarify.

Key words: Aspergillus carbonarius. Ochratoxin A. Agrobacterium tumefaciens. Genetic transformation. Insertional mutants.

\section{Introdução}

As exigências no controle de qualidade e nas condições higiênico-sanitárias dos produtos são fundamentais e estão se tornando cada vez mais rigorosas, especialmente para os produtos destinados à alimentação humana e animal. Contaminações em alimentos causadas por fungos têm sido assunto de diversas pesquisas no mundo. Estima-se que aproximadamente $25 \%$ da produção anual de alimentos derivados de plantas são deteriorados por fungos. Parte destes fungos tem potencial para a produção de micotoxinas e representam um dos fatores de preocupação para a saúde.

As micotoxinas são metabólitos secundários produzidos por algumas espécies fúngicas (VARGA et al., 2003). Dentre as micotoxinas mais comumente encontradas em alimentos, a ocratoxina A tem despertado atenção mundial pelas suas propriedades nefrotóxica, imunossupressiva, teratogênica e carcinogênica (LEA; STEIEN; STORMER, 1989). Por sua ação, a ocratoxina A foi classificada pela "International Agency for Research on Cancer" como um possível carcinógeno para humanos (categoria 2B) (KUIPER-GOODMAN; SCOTT, 1989; PETZINGER; ZIEGLER, 2000).

A presença de ocratoxina $\mathrm{A}$ em alimentos vem sendo considerada um problema mundial de saúde pública. Em uma grande variedade de produtos agrícolas em várias regiões geográficas do mundo já foi detectada a ocratoxina A (URBANO et al., 2001). Muitos destes alimentos são grãos, como cevada, milho, centeio, trigo e aveia (JORGENSEN; JACOBSEN, 2002), além de estar presente em outros produtos incluindo café, especiarias, nozes, azeitonas, uvas, e figos (BATTILANI et al., 2003; BATISTA et al., 2003; BAYMAN et al., 2002; JORGENSEN,
1998). A ocratoxina sobrevive a processamentos e pode ser encontrada em pães (SCUDAMORE; BANKS; MCDONALD, 2003), café bebida (PITTET, et al., 1996), vinhos (CABAÑES et al., 2002) e cervejas (ODHAV; NAICKER, 2002).

A ocratoxina A foi originalmente isolada como um metabólito secundário do fungo filamentoso Aspergillus ochraceus (VAN DER MERWE, et al, 1965). Em anos subseqüentes, muitas outras espécies de Aspergillus como A. niger, A. carbonarius, A. sulphureus e A. melleus (ABARCA et al., 1994; CIEGLER, 1972) entre outras foram descritas como produtoras de ocratoxina A. Dentre as espécies do gênero Aspergillus produtoras desta micotoxina, Aspergillus carbonarius tem se destacado por ser considerada uma das maiores fontes de contaminação de ocratoxina A em alimentos como frutas secas, vinho e café (MAGNOLI et al., 2003; CABAÑES et al., 2002; PARDO et al., 2004).

Algumas informações sobre a composição química da ocratoxina A são conhecidas. Sabe-se que esta toxina é derivada da dihidroisocumarina ligado a um grupo L- $\beta$ fenilalanina mediante uma ligação amida (HARRIS; MANTLE, 2001) e apresenta uma molécula de cloro em sua estrutura responsável pelo seu caráter tóxico. No entanto, o conhecimento da via biossintética desta micotoxina é ainda muito limitado. Até o momento foram descritos três genes relacionados à biossíntese da ocratoxina $\mathrm{A}$ em $A$. ochraceus. Um destes genes foi denominado $p k s \mathrm{e}$ codifica uma policetídeo sintase, similar a policetídeos sintases fúngicas envolvidas na biossíntese de outras micotoxinas (O'CALLAGHAN; CADDICK; DOBSON, 2003). Outros dois genes envolvidos na via biossintética são tipos de monooxigenases p450, denominados gene $p 450-H 11$ e gene $p 450-B 03$ (O'CALLAGHAN; STAPLETON; DOBSON, 2006). 
Para A. carbonarius, nenhum gene envolvido em passos da biossíntese da ocratoxina A foi descrito. Diferentes procedimentos podem ser utilizados para a identificação destes genes e um deles é o uso de mutantes insercionais. Dos métodos para obtenção destes mutantes, a transformação genética mediada por Agrobacterium tumefaciens tem sido muito utilizada. Esta metodologia, para fungos filamentosos, foi descrita por De Groot et al. (1998) e faz uso da bactéria de solo aeróbia Gram-negativa $A$. tumefaciens que já há muitos anos vem sendo utilizada para a transferência de genes em plantas (TINLAND, 1996) e também amplamente explorada para clonar genes, promotores, e seqüências regulatórias.

Uma das vantagens da transformação via $A$. tumefaciens em relação aos outros métodos é a praticidade, uma vez que dispensa a obtenção de protoplastos e o uso de equipamentos de alto custo. Além disso, tem-se alta eficiência de transformação e a predominância de transformantes com o DNA exógeno integrado em cópia única ao genoma (DE GROOT ET AL. 1998; MULLINS et al., 2001). Essas características fazem deste sistema um importante método de análise genética de fungos filamentosos, como para estudos de nocaute e expressão gênica.

Neste trabalho descreve-se a transformação genética via $A$. tumefaciens para a linhagem ITAL 187 de A. carbonarius e a seleção de mutantes insercionais para a produção de ocratoxina A. Estes mutantes estão disponíveis na micoteca do Laboratório de Genética de Biologia Molecular da UEL e podem ser utilizados em estudos posteriores relacionados à identificação e clonagem de genes envolvidos em passos da via biossintética da ocratoxina A.

\section{Metodologia}

Linhagem de Agrobacterium tumefaciens e do isolado fúngico

A linhagem AGL1 de A. tumefaciens (ATCC/ BAA-101), gentilmente cedida pelo Dr. C. Peter
Romaine da Universidade da Pensilvânia (EUA), foi utilizada para realizar a transformação genética. Esta linhagem foi inoculada em meio Luria-Bertani (LB) contendo os antibióticos estreptomicina $(50 \mathrm{mg} / \mathrm{mL})$ e canamicina $(50 \mathrm{mg} / \mathrm{mL})$ para a manutenção do sistema binário: plasmídio Ti desarmado + vetor binário pPK2 $(10,77 \mathrm{~Kb})$. Este vetor, derivado do pPZP201 (HAJDUKIEWICS; SAVAB; MALIGA, 1994), possui as bordas esquerda e direita do T-DNA flanqueando o gene da fototransferase (gene $h p h$ ) de Escherichia coli, que confere resistência a higromicina B. Este gene é controlado pelo promotor gpd (gliceraldeído 3-fosfato desidrogenase) e pela seqüência terminal $\operatorname{trp} C$ (síntese de triptofano), ambos de Aspergillus nidulans. No plasmídio Ti encontra-se o gene kan, marcador genético para resistência a canamicina.

A linhagem fúngica de $A$. carbonarius transformada foi a ITAL 187. Esta linhagem foi gentilmente cedida pela $\mathrm{Dr}^{\mathrm{a}}$. Marta Hiromi Taniwaki do Instituto de Tecnologia de Alimentos em Campinas (ITAL). Trata-se de uma linhagem isolada de grãos de café e previamente caracterizada como altamente produtora de ocratoxina A pelo ITAL.

Teste de sensibilidade da linhagem fúngica a higromicina $B$

Antes dos experimentos de transformação, a linhagem ITAL 187 foi avaliada para a determinação da concentração inibitória mínima (CIM). A CIM permite determinar qual é a concentração mínima de higromicina $B$ em que o crescimento do fungo é inibido. $\mathrm{O}$ valor do CIM encontrado foi utilizado para a posterior seleção dos transformantes.

Para isto, a linhagem fúngica foi inoculada em placas de Petri contendo $20 \mathrm{~mL}$ de meio completo (MC) de Pontecorvo et al. (1953) acrescido de quantidades crescentes de higromicina $\mathrm{B}(0,15,25$, $50,75,100,150$ e $200 \mathrm{mg} / \mathrm{mL}$ ). Após 7 dias de incubação foi feita a leitura da capacidade de crescimento nas diferentes concentrações de higromicina $\mathrm{B}$ e a determinação do CIM. 
Transformação genética mediada por A. tumefaciens

A transformação genética da linhagem ITAL 187 foi realizada como descrito por Morioka et al. (2006) com algumas modificações. Rapidamente, após cinco dias de crescimento da linhagem ITAL 187 em MC a $28^{\circ} \mathrm{C}$, foi preparada uma suspensão contendo $1 \times 10^{6}$ conídios/mL de meio de indução. A linhagem AGL1 foi inoculada em meio LB suplementado com estreptomicina $(50 \mathrm{mg} / \mathrm{mL})$ e canamicina $(50 \mathrm{mg} / \mathrm{mL})$ e mantida a $28^{\circ} \mathrm{C}$ e $180 \mathrm{rpm}$ durante 12 horas. Após este período, esta cultura foi diluída para uma densidade óptica (D.O.), a $\mathrm{A}_{660 \mathrm{~nm}}$, de 0,15 em meio de indução. A cultura foi mantida a $28^{\circ} \mathrm{C}$ e $180 \mathrm{rpm}$ até atingir D.O. ${ }_{660 \mathrm{~mm}}$ entre 0,6 e 0,8 . Nestas condições este tempo de indução foi de aproximadamente seis horas.

Após este período, as suspensões de bactéria (com D.O. ${ }_{660 \mathrm{~mm}}$ entre 0,6 e 0,8$)$ e do fungo $\left(1 \times 10^{6}\right.$ conídios/ $\mathrm{mL})$ foram misturadas em igual proporção $(1: 1,100$ $\mu \mathrm{L})$. Esta mistura foi plaqueada em membrana de nitrocelulose $(0,45 \mathrm{~mm}$ de porosidade e $90 \mathrm{~mm}$ de diâmetro, MFS, Japão) posicionadas sobre meio de indução sólido contendo acetoseringona $(200 \mathrm{mM}) \mathrm{e}$ incubadas a $28^{\circ} \mathrm{C}$ por 36 horas (período denominado co-cultivo). Após este tempo, as membranas foram transferidas para placas de Petri contendo meio seletivo sólido M-100, suplementado com $150 \mu \mathrm{g} / \mathrm{mL}$ de cefoxitina (Eurofarma) e $75 \mu \mathrm{g} / \mathrm{mL}$ de higromicina B (Invitrogen) para seleção dos transformantes. A concentração de higromicina B utilizada para a seleção dos transformantes foi maior que o valor encontrado pelo CIM.

As colônias visualizadas após 4 a 5 dias foram contadas e repicadas em placas de Petri contendo meio MC, suplementado com $75 \mu \mathrm{g} / \mathrm{mL}$ de higromicina $\mathrm{B}$, e incubadas até a conidiogênese.

\section{Avaliação fenotípica dos transformantes}

Os transformantes foram repicados em placas de Petri contendo meio MC acrescido de $75 \mu \mathrm{g} / \mathrm{mL}$ de higromicina B. Após 5 dias de crescimento, os transformantes foram analisados quanto à capacidade de esporulação e coloração dos esporos assexuais, comparando com a linhagem selvagem. As colônias que apresentaram esporulação reduzida e/ou coloração alterada foram classificadas como mutantes morfológicos.

Análise dos transformantes quanto ao nível de resistência a higromicina $B$

Para determinar o nível de resistência a higromicina $\mathrm{B}$, um total de 26 transformantes foi inoculado em placas de 26 pontos, contendo meio MC sólido em diferentes concentrações de higromicina B $(0,25,50,75,150,300,600,900 \mathrm{e}$ $1200 \mathrm{mg} / \mathrm{mL}$ ). A linhagem selvagem foi utilizada como controle.

Seleção de mutantes para produção de ocratoxina A

Os transformantes foram analisados quanto à capacidade de produção de ocratoxina A em placas de Petri contendo meio de cultura ágar-coco, conforme descrito por Heenan, Shaw e Pitt (1998). Em cada placa foi inoculado um transformante juntamente com a linhagem selvagem e, após 5 dias de crescimento, as placas foram analisadas sob luz ultravioleta em que a ocratoxina A torna-se fluorescente. As colônias transformantes que apresentaram alteração na fluorescência azul esverdeada em relação à linhagem selvagem, foram consideradas possíveis mutantes para ocratoxina A. Estas colônias foram selecionadas para posterior análise em HPLC.

Confirmação do fenótipo mutante para ocratoxina A pelo método de Cromatografia Líquida de Alto Desempenho (HPLC)

A metodologia usada para análise em HPLC foi descrita por Bragulat, Abarca e Cabañes (2001). Os mutantes selecionados foram inoculados em placas de Petri contendo meio extrato de levedura-sacarose (YES). As placas foram incubadas por 5 dias a $28^{\circ} \mathrm{C}$. Após este período, três áreas de $0,5 \times 0,5 \mathrm{~cm}$ foram recortadas do meio, pesadas e submetida à extração da micotoxina com metanol. Cada amostra foi filtrada 
(Millex-Millipore, Massachusetts, USA) e injetada no sistema HPLC. O equipamento de HPLC usado foi o Shimadzu LC-10VP System (Shimadzu, Japan) com um detector de fluorescência de $333 \mathrm{~nm}$ de excitação e $477 \mathrm{~nm}$ de emissão. O HPLC foi ajustado com uma coluna de guarda Shimadzu CLC G-ODS (4 x $10 \mathrm{~mm}$ ) e uma coluna Shimadzu Shimpack CLC-ODS $(4.6 \times 250 \mathrm{~mm})$. A fase móvel foi metanol: acetonitrila: água deionizada: ácido acético (35:35:29:10) e a taxa de fluxo foi $0,8 \mathrm{~mL} / \mathrm{min}$. Uma ocratoxina A padrão (Sigma Chemical, St Louis, USA) foi usada para a construção de uma curva de calibração, área de pico versus massa (ng). A concentração de ocratoxina A no extrato da amostra foi determinada pela interpolação da área de pico resultante a partir do gráfico de calibração.

\section{Extração de DNA genômico}

Foram escolhidos 14 transformantes ao acaso e a linhagem selvagem para a extração do DNA genômico. Para cada transformante e para a linhagem selvagem foi realizada uma suspensão de conídios em tween 80 e inoculada em frascos tipo erlenmeyer contendo MC líquido. Decorrido 24 horas de incubação a $28^{\circ} \mathrm{C}$ e $180 \mathrm{rpm}$ o micélio foi coletado por filtração e submetido à extração de ácidos como descrito por Azevedo et al. (2000).

\section{Análise dos transformantes pela Reação da Polimerase em Cadeia (PCR)}

A presença do fragmento do gene $h p h$ que confere resistência a higromicina B foi confirmada nos transformantes por PCR. Cada reação de amplificação foi preparada para um volume final de $25 \mu \mathrm{L}$, contendo $2,5 \mu \mathrm{L}$ de tampão (200 mM Tris$\mathrm{HCl} \mathrm{pH} \mathrm{8,4,500} \mathrm{mM} \mathrm{KCl,} \mathrm{10x} \mathrm{concentrado,} \mathrm{Invitrogen}$ - Life Technologies); 2,0 $\mu \mathrm{L}$ de dNTP $(2,5 \mathrm{mM}$, Invitrogen - Life Technologies); $1,0 \mu \mathrm{L}$ de $\mathrm{MgCl}_{2}$ (50 $\mathrm{mM}$, Invitrogen - Life Technologies); $1,5 \mu \mathrm{L}$ de primer hph 1 (5'-TTCGATGTAGGAGGGCGTGGAT-3') e 1,5 $\mu \mathrm{L}$ hph 2 (5'-CGCGTCTGCTGCTCCATAC-3') (10 pmol/mL, Invitrogen - Life Technologies); $0,2 \mu \mathrm{L}$ de Taq DNA polimerase $(5 \mathrm{U} / \mathrm{mL}$, Invitrogen - Life
Technologies); $3 \mu \mathrm{L}$ da amostra de DNA (5 ng/mL). $\mathrm{O}$ volume final foi completado com água ultrapura. Para amplificação foi utilizado o termociclador PTC100 (MJ RESEARCH, INC). As condições de ciclagem foram utilizadas conforme descrito por Malonek e Meinhardt (2001).

Análise da integração do DNA exógeno nos transformantes por Southern Blot

Para a análise por Southern Blot os DNAs extraídos foram inicialmente tratados com RNAse A (Invitrogen - Life Technologies). O tratamento foi realizado da seguinte forma: diluiu-se o DNA genômico para $100 \mathrm{ng} / \mu \mathrm{L}$ e, a este, adicionou-se 1 $\mu \mathrm{L}$ de RNA A (20 mg/mL) completando o volume para $100 \mu \mathrm{L}$ de água esterelizada. A reação foi incubada a $37^{\circ} \mathrm{C}$ (em banho-maria) por 30 minutos e, após este tempo, a reação foi interrompida por aquecimento a $65^{\circ} \mathrm{C}$ por 5 minutos. Após este tratamento com RNAse, os DNAs foram submetidos à hidrólise com a enzima de restrição SstI (Invitrogen, Life Technologies) a $10 \mathrm{U} / \mathrm{mL}$. Esta enzima reconhece e cliva uma sequiência de nucleotídeos presente em uma das extremidades do cassete de expressão. A reação de restrição foi feita em um volume total de $100 \mu \mathrm{L}$, contendo $5 \mu \mathrm{g}$ de DNA, $10 \mu \mathrm{L}$ de tampão React ${ }^{\circledR} 2$ (10\% do volume total, Invitrogen - Life Technologies) e $20 \mathrm{U}$ da enzima SstI $(2 \mu \mathrm{L})$. A reação foi incubada a $37^{\circ} \mathrm{C}$ (em banho-maria) durante 12 horas, e após este período a enzima foi inativada por aquecimento a $65^{\circ} \mathrm{C}$ por 10 minutos. Para concentrar a amostra hidrolisada foi feita uma precipitação adicionando-se $10 \mu \mathrm{L}$ de $\mathrm{NaCl}(3 \mathrm{M})$ e $250 \mu \mathrm{L}$ de álcool etílico absoluto gelado. Após incubação a $-20^{\circ} \mathrm{C}$ por 12 horas, o material foi centrifugado $(10.000 \mathrm{rpm}$ por 10 minutos) e o precipitado foi lavado com álcool $70 \%$. Após secagem em temperatura ambiente, o DNA hidrolisado foi ressuspenso em $10 \mu \mathrm{L}$ de água estéril. Os $10 \mu \mathrm{L}$ de DNA hidrolisado foram colocados em gel de agarose $0,8 \%(\mathrm{p} / \mathrm{v})$. A eletroforese foi realizada a $3 \mathrm{~V}$ por $\mathrm{cm}$ de distância entre os eletrodos. Após a eletroforese, o DNA foi transferido para uma membrana de náilon (HYBOND-N - AMERSHAM), conforme descrito em Brasileiro e Carneiro (1998). 
Hibridação do DNA genômico dos transformantes

A hidridação foi realizada conforme recomendado pelo protocolo do Kit "DIG High Prime DNA Labelling and Detection Starter Kit II" (Roche). A membrana, contendo o DNA genômico restringido dos transformantes e linhagem controle, foi colocada em saco plástico contendo $4,24 \mathrm{~mL}$ de solução de pré-hibridação (como fornecida pelo Kit) e incubada a $42^{\circ} \mathrm{C}$, sob agitação de $50 \mathrm{rpm}$, por 30 minutos. Decorrido este tempo, a solução de pré-hibridação foi retirada. Cerca de $106 \mathrm{ng}$ de sonda previamente desnaturados a $100^{\circ} \mathrm{C}$ por 5 minutos seguido de resfriamento em gelo, foram suspensos em $4,24 \mathrm{~mL}$ de solução de hibridação, e então colocados no saco plástico contendo a menbrana. A membrana foi incubada por 18 horas a $42^{\circ} \mathrm{C}$, sem agitação.

Após hibridação, a membrana foi inicialmente lavada duas vezes com SSC $2 x$, SDS $0,1 \%$ por 5 minutos a $28^{\circ} \mathrm{C}$, com agitação branda, e mais duas vezes com SSC $0,5 x$, SDS $0,1 \%$ por 15 minutos a $68^{\circ} \mathrm{C}$, agitação branda. Em seguida, foi lavada em tampão de lavagem (ácido maléico $0,1 \mathrm{M} ; \mathrm{NaCl} 0,15$ M; Tween $200,3 \%(\mathrm{v} / \mathrm{v}), \mathrm{pH} 7,5)$ por 5 minutos a $30^{\circ} \mathrm{C}$ e $50 \mathrm{rpm}$, e incubada em $121 \mathrm{~mL}$ de solução de bloqueio (fornecida pelo Kit), diluído 1:10 em tampão de ácido maléico (ácido maléico $0,1 \mathrm{M} ; \mathrm{NaCl} 0,15$ $\mathrm{M}, \mathrm{pH} 7,5$ ), por 30 minutos a $30^{\circ} \mathrm{C}$ e $50 \mathrm{rpm}$. A membrana ainda foi incubada por 30 minutos a $30^{\circ} \mathrm{C}$ e agitação branda em $24,2 \mathrm{~mL}$ de solução de anticorpo (fornecida pelo Kit), anteriormente diluída 1:10000 em solução de bloqueio 1:10, e novamente lavada duas vezes em tampão de lavagem por 15 minutos a $30^{\circ} \mathrm{C}$ e $50 \mathrm{rpm}$. Por último, a membrana foi incubada em 24,2 mL de tampão de detecção ( $\mathrm{NaCl} 0,1 \mathrm{M}$; Tris-HCl 0,1 M pH 9,5) por 5 minutos a $30^{\circ} \mathrm{C}$ e agitação branda. A membrana foi colocada sobre uma folha de transparência e em sua face contendo o DNA foram aplicados $121 \mathrm{~mL}$ de CSPD (fornecido pelo Kit). Em seguida a membrana foi coberta com outra folha de transparência e incubada por mais 5 minutos a $30^{\circ} \mathrm{C}$. O excesso de líquido entre as folhas de transparência, entre as quais estava a membrana, foi retirado rolando-se um bastão de vidro sobre elas. A membrana foi incubada por 10 minutos a $37^{\circ} \mathrm{C}$ e exposta a filme de raio-X (IBF-MEDIX AGFA) durante 1 hora e 30 minutos. Após a exposição, o filme foi revelado no aparelho GLUNZ \& JENSEN modelo MULTI-X 36.

\section{Resultados e Discussão}

Inicialmente a linhagem ITAL 187 de $A$. carbonarius foi testada quanto a sua sensibilidade à higromicina B. Na análise de diferentes concentrações do antibiótico, o crescimento do fungo foi totalmente inibido em placas de MC que continham pelo menos $50 \mu \mathrm{g} / \mathrm{mL}$ de higromicina B (CIM). Este nível de sensibilidade foi similarmente observado para outras espécies de Aspergillus (PUNT et al., 1987) e já havia sido relatada para a linhagem ITAL 99 de A. carbonarius por Morioka et al. (2006). Portanto, foram utilizados $75 \mu \mathrm{g} / \mathrm{mL}$ de higromicina B para a seleção dos transformantes resistentes a este antibiótico.

O co-cultivo de A. carbonarius com A. tumefaciens resultou em colônias resistentes à higromicina $\mathrm{B}$ após 4 a 5 dias da transferência das membranas do co-cultivo para o meio seletivo. Em média a freqüência de transformação (quatro experimentos de transformação independentes) foi de 20,04 transformantes para cada $10^{5}$ conídios.

A análise de 25 transformantes quanto ao nível de resistência a higromicina mostrou que $100 \%$ deles eram capazes de crescer em concentração de até $150 \mu \mathrm{g} / \mathrm{mL}$ de higromicina B. No entanto o nível máximo de resistência à higromicina foi variável dentre os transformantes. Esta variação pode ser decorrente no número de cópias do gene $h p h$ no genoma fúngico ou do local de integração do gene de resistência.

A prova física da transformação foi obtida através da detecção da amplificação de uma porção do gene $h p h$. Em todos os 14 transformantes analisados detectou-se, como esperado, um fragmento de 600 pb (Figura 1). 


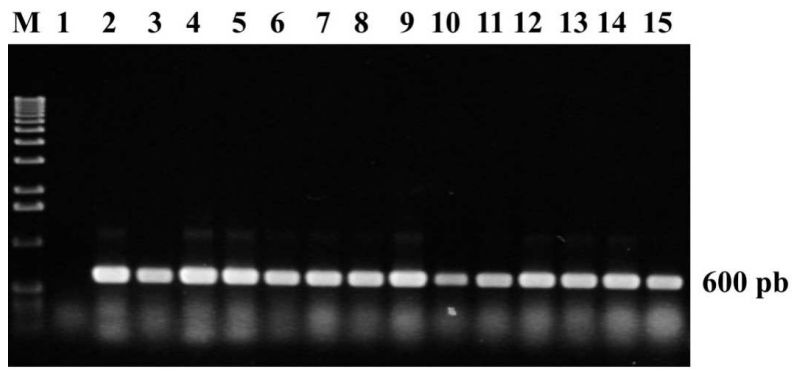

Figura 1. Prova física da transformação obtida através da detecção do gene exógeno $h p h$ por reações de PCR. M: marcador; 1: controle negativo (selvagem); 2-15: transformantes.

A aleatoriedade da integração do gene $h p h$ no genoma fúngico é um parâmetro importante quando se deseja obter mutações insercionais ao acaso. A Figura 2 mostra o resultado do Southern Blot realizado com sete transformantes escolhidos ao acaso. As diferenças de massas moleculares dos fragmentos revelados mostram a aleatoriedade da integração e conseqüentemente a potencialidade do método para a seleção de mutantes aleatórios.

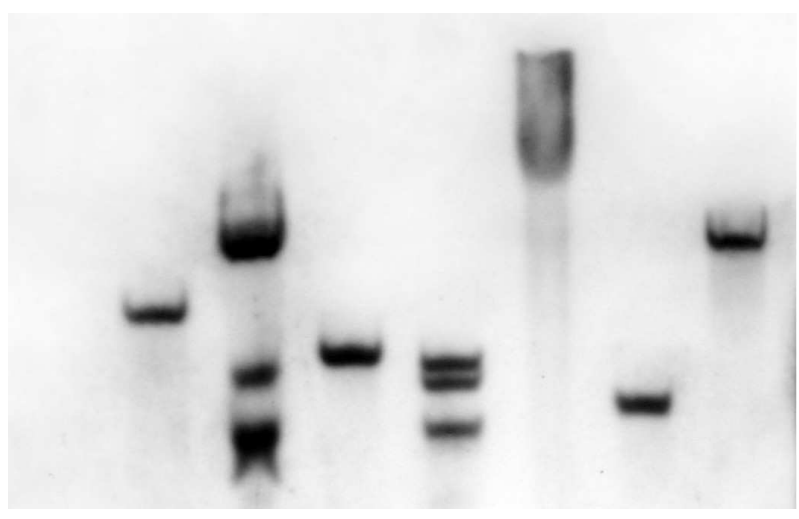

Figura 2. Análise da integração do gene $h p h$ nos transformantes por Southern Blot C: controle negativo (selvagem); 1-7: T32, T44, T47, T104, T162, T188, T238.

A eficiência deste método para a obtenção de mutantes de A. carbonarius revelou-se na medida em que foram obtidos mutantes morfológicos e/ou com alteração na produção de ocratoxina $\mathrm{A}$. A análise fenotípica de 238 transformantes demonstrou que 12 deles $(5,04 \%)$ apresentaram alterações morfológicas, como redução da capacidade de crescimento e esporulação e alteração na coloração dos esporos assexuais, em comparação com a linhagem original de A. carbonarius.
Dentre os 238 transformantes analisados em meio agar-coco para a produção de ocratoxina $\mathrm{A}$, nove $(3,7 \%)$ possíveis mutantes com redução da produção desta toxina foram identificados baseado na redução e/ou ausência de fluorescência azul esverdeada na colônia sob luz ultravioleta. Por outro lado, dois $(0,8 \%)$ supostos mutantes com aumento na produção desta toxina também foram identificados. Nestes mutantes, a fluorescência encontrada foi visualmente maior quando comparada com a fluorescência da linhagem selvagem.

A capacidade destes onze possíveis mutantes de produzir ocratoxina A foi analisada por HPLC. Esta metodologia permitiu quantificar a redução ou aumento da ocratoxina A dos mutantes em relação à linhagem selvagem. Dos nove possíveis mutantes analisados, três ( $\mathrm{T}$ 44, T 47, T 188) mostraram-se com significativa redução da produção de ocratoxina A. O aumento na produção desta toxina foi confirmada nos dois mutantes analisados em meio agar-coco (T 238 e T 162). A quantificação da produção da ocratoxina A por estes mutantes é demonstrada na Tabela 1.

Tabela 1. Quantificação da ocratoxina A por HPLC.

\begin{tabular}{c|c|c}
\hline Amostras & Ocratoxina $\left(\mu \mathrm{g} \cdot \mathrm{Kg}^{-1}\right)$ & $\%$ relativa \\
\hline ITAL 187 (selvagem) & 3650.89 & 100 \\
T 188 & 61.60 & 1.69 \\
T 44 & 103.68 & 2.84 \\
T 47 & 298,27 & 8,17 \\
T 162 & 39973.00 & --- \\
T 238 & 22685,67 & ---- \\
\hline
\end{tabular}

Os resultados apresentados neste trabalho mostram pela primeira vez que a transformação mediada por Agrobacterium tumefaciens é um importante mutagênico para $A$. carbonarius. Os mutantes de $A$. carbonarius com produção reduzida e aumentada de ocratoxina estão disponíveis na micoteca do Laboratório de Genética de Biologia Molecular da UEL e podem ser utilizados em estudos relacionados à identificação e clonagem de genes envolvidos em passos da via biossintética desta micotoxina. 


\section{Agradecimentos}

Ao CNPq pela bolsa de iniciação científica concedida. À Fundação Araucária, FINEP e CNPq pelo apoio financeiro.

\section{Referências}

ABARCA, M. L.; BRAGULAT, M. R.; CASTELLA, G.; CABANES, F. J. Ochratoxin A production by strains of Aspergillus niger var. niger. Applied and Environmental Microbiology, Washington, v.60, n.7, p.2650-2652, 1994.

AZEVEDO, A. C. S.; FURLANETO, M. C.; SOSA-GOMEZ, D. R.; FUNGARO, M. H. P. Molecular characterization of Paecilomyces fumoroseus (Deuteromycotina Hyphomycetes) isolates. Scientia Agrícola, Piracicaba, v.57, p.729-732, 2000.

BATISTA, L. R.; CHALFOUN, S. M.; PRADO, G.; SCHWAN, R. F.; WHEALS, A. E. Toxigenic fungi associated with processed (green) coffee beans (Coffea arabica L.). International Jounal of Food Microbiology, Amsterdam, v.85, n.3, p.293-300, aug. 2003.

BATTILANI, P.; PIETRI, A.; BERTUZZI, T.; LANGUASCO, L.; GIORNI, P.; KOZAKIEWICZ, Z. Occurrence of ochratoxin A-producing fungi in grapes grown in Italy. Journal of Food Protection, Des Moines, v.66, n.4, p.633-666, apr. 2003.

BAYMAN, P. Ochratoxin production by the Aspergillus ochraceus group and Aspergillus alliaceus. Applied and Environmental Microbiology, Washington, v.68, n.4, p.2326-2329, 2002.

BRAGULAT, M. R.; ABARCA, M. L.; CABAÑES, F. J. An easy screening method for fungi producing ochratoxin A in pure culture. International Journal of Food Microbiology, Amsterdam, v.71, n.2/3, p.139-144, 2001.

BRASILEIRO, A. C. M.; CARNEIRO, V. T. C. C. Manual de transformação genética de plantas. Brasília: SPI/ EMBRAPA, 1998.

CABAÑES, F. J.; ACCENSI, F., BRAGULAT, M. R; ABARCA, M. L.; CASTELLA, G. MINGUEZ, S.; PONS, A. What is the source of ochratoxin A in vine? International Journal of Food Microbiology, Amsterdam, v.79, n.3, p.213-215, dec. 2002.

CIEGLER, A. Bioproduction of ochratoxin A and penicillic acid by members of the Aspergillus ochraceus group. Canadian Journal of Microbiology, Ottawa, v.18, n.5, p.631-636, 1972.

DE GROOT, M. J. A; BUNDOCR, P.; HOOYKAAS, P. J. J.; BEIJERS BERGEN, A. G. M. Agrobacterium tumefaciens- mediated transformation of filamentous fungi. Nature Biotechnology, New York, v.16, n.11, p.839-842, nov. 1998.

HAJDUKIEWICZ, P.; SVAB, Z.; MALIGA, P. The small versatile pPZP family of Agrobacterium binary vectors for plant transformation. Plant Molecular Biology, New York, v.25, n.6, p.989-994, sep. 1994.

HARRIS, J. P.; MANTLE, P. G. Biosynthesis of ochratoxins by Aspergillus ochraceus. Phytochemistry, New York, v.58, n.5, p.709-716, nov. 2001.

HEENAN, C. N.; SHAW, K. J.; PITT, J. J. Ochratoxin A production by Aspergillus carbonarius and A. niger isolates and detection using coconut cream agar. Journal of Food Mycology, Great Britain, v.1, p.67-72, 1998.

JORGENSEN, K. A survey of pork, poultry, coffee, beer and pulses for ochratoxin A. Food Additives and Contaminants, London, v.15, n.5, p.550-554, jul. 1998.

JORGENSEN, K.; JACOBSEN, J. S. Occurrence of ochratoxin A in Danish wheat and rye, 1992-1999. Food Additives and Contaminants, London, v.19, n.12, p.11841189, 2002.

KUIPER-GOODMAN, T.; SCOTT, P. M. Review: risk assessment of the mycotoxin ochratoxin A. Biomedical and Environmental Sciences, San Diego, v.2, p.179-248, 1989.

LEA, T.; STEIEN, K.; STORMER, C. Mechanism of ochratoxin A-induced immunosuppression. Mycopathologia, Den Haag, v.107, n.2/3, p.153-159, sep. 1989.

MAGNOLI, C.; VIOLANTE, M.; COMBINA, M.; PALACIO, G.; DALCERO, A. Mycoflora and ochratoxinproduction strains of Aspergillus section Nigri in wine grapes in Argentina. Letters in Applied Microbiology, Oxford, v.37, n.2, p.179-183, 2003.

MALONEK, S; MEINHARDT, F. Agrobacterium tumefaciens-mediated genetic transformation of the phytopathogenic ascomucete Calonectria morganii. Current Genetics, New York, v.40, n.2, p.152-155, sep. 2001.

MORIOKA, L. R. I.; FURLANETO, M. C.; BOGAS, A. C.; POMPERMAYER, P.; DUARTE, R. T. D.; VIEIRA, M. L.C.; WATANABE, M. A. E.; FUNGARO, M. H. P. Efficient genetic transformation system for the ochratoxigenic fungus Aspergillus carbonarius. Current Microbiology, New York, v.52, n.6, p.469-472, jun. 2006.

MULLINS, E. D.; CHEN, X.; ROMAINE, P.; RAINA, R.; GEISER, D. M.; KANG, S. Agrobacterium-mediated transformation of Fusarium oxysporum: an efficient tool for insertional mutagenesis and gene transfer. Phytopathology, Saint Paul, v.91, n.2, p.73-180, feb. 2001. 
O'CALLAGHAN, J.; CADDICK, M. X.; DOBSON, A. D. W. A polyketide synthase gene required for ochratoxin A biosynthesis in Aspergillus ochraceus. Microbiology, Reading, v.149, p.3485-3491, 2003.

O’CALLAGHAN, J.; STAPLETON, P. C.; DOBSON, A. D. W. Ochratoxin A biosynthetic genes in Aspergillus ochraceus are differentially regulated by $\mathrm{pH}$ and nutricional stimuli. Fungal Genetics and Biology, Orlando, v.43, n.4, p.213-221, 2006.

ODHAV, B.; NAICKER, V. Mycotoxins in South-African traditionally brewed beers. Food Additives and Contaminants, London, v.19, n.1, p.55-61, jan. 2002.

PARDO, E.; MARIN, S.; RAMOS, A.; SANCHIS, V. Occurrence of ochratoxin fungi and ochratoxin A in green coffee from different origins. Food Science and Technology International, London, v.10, n. 1, p.45-49, feb. 2004.

PETZINGER, E.; ZIEGLER, K. Ochratoxin A from a toxicological perspective. Journal of Veterinary Pharmacology and Therapeutics, Oxford, v.23, n.2, p.9198, apr. 2000.

PITTET, A.; TORNARE, D.; HUGGETT, A.; VIANI, R. Liquid chromatographic determination of ochratoxin A in pure and adulterated soluble coffee using an immunoaffinity columm cleanup procedure. Journal of Agricultural and Food Chemistry, Easton, v.44, n.11, p.3564-3569, nov. 1996.
PONTECORVO, G.; ROPER, J. A; HEMMONS, L. M.; MACDONALD, K. D.; BUFTON, A. W. J. The genetics of Aspergillus nidulans. Advances in Genetics, New York, v.5, p.141-148, 1953.

PUNT, P. J.; OLIVER, R. P.; DINGEMANSE, M. A.; POUWELS, P. H.; VANDENHONDEL, C. A. M. J. J. Transformation of Aspergillus based on the hygromycin B resistance marker from Escherichia coli. Gene, Amsterdam, v.56, n.1, p.117-124, 1987.

SCUDAMORE, K. A.; BANKS, J.; MCDONALD, K. J. The fate of ochratoxin A in the processing of whole wheat grains during milling and bread production. Food Additives and Contaminants, London, v.20, n.12, p.11531163, dec. 2003.

TINLAND, B. The integration of T-DNA in plant genomes. Trends in Plant Science, Oxford, v.1, p.178-184, 1996.

URBANO, G. R.; TANIWAKI, M. H.; LEITAO, M. F.D.; VICENTINI, M. C. Occurrence of ochratoxin A-producing fungi in raw Brazilian coffee. Journal of Food Protection, Des Moines, v.64, n.8, p.1226-1230, aug. 2001.

VANDERME, K. J.; STEYN, P. S.; FOURIE, L.; SCOTT, D. B; THERON, J. J. Ochratoxin A, a toxic metabolite. Nature, London, v.65, p.1112-1113, 1965.

VARGA, J.; RIGO, K.; TOTH, B.; TEREN, J.; KOZAKIEWICZ, Z.Evolutionary relationships among Aspergillus species producing economically important mycotoxins. Food Technology and Biotechnology, Zagreb, Croatia, v.41, n.1, p.29-36, 2003. 
